\title{
Comparison of Clinico-Pathological Presentations of Triple- Negative versus Triple-Positive and HER2 Iraqi Breast Cancer Patients
}

\author{
Nada A. S. Alwan , Furat N. Tawfeeq
}

National Cancer Research Center, University of Baghdad, Baghdad, Iraq

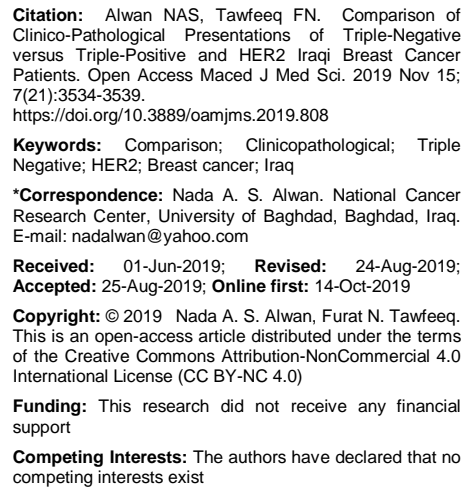

Competing Interests: The authors have declared that no competing interests exist

\begin{abstract}
BACKGROUND: Breast cancer remains the most common malignancy among the Iraqi population. Affected patients exhibit different clinical behaviours according to the molecular subtypes of the tumour.

AIM: To identify the clinical and pathological presentations of the Iraqi breast cancer subtypes identified by Estrogen receptors (ER), Progesterone receptors (PR) and HER2 expressions.

PATIENTS AND METHODS: The present study comprised 486 Iraqi female patients diagnosed with breast cancer. ER, PR and HER2 contents of the primary tumours were assessed through immunohistochemical staining; classifying the patients into five different groups: Triple Negative (ER/PR negative/HER2 negative), Triple Positive (ER/PR positive/HER2 positive), Luminal A (ER/PR positive/HER2 negative), HER2 enriched ((ER/PR negative/HER2 positive) and all other subtypes.

RESULTS: The major registered subtype was the Luminal A which was encountered in 230 patients $(47.3 \%)$, followed by the Triple Negative (14.6\%), Triple Positive (13.6\%) and HER2 Enriched (11.5\%). Patients exhibiting the Triple Negative subtype were significantly younger than the rest of the groups and presented with larger size tumours. A significant difference in the distribution of the breast cancer stages was displayed $(p<0.05)$; the most advanced were noted among those with HER2 enriched tumours who exhibited the highest frequency of poorly
\end{abstract} differentiated carcinomas and lymph node involvement.

CONCLUSION: The most significant variations in the clinicopathological presentations were observed in the age and clinical stage of the patients at diagnosis. Adoption of breast cancer molecular subtype classification in countries with limited resources could serve as a valuable prognostic marker in the management of aggressive forms of the disease.

\section{Introduction}

The burden of breast cancer, as the most prevalent malignant neoplasm among females globally [1] and in Iraq specifically [2], has been illustrated comprehensively in numerous surveys that emphasised the importance of its early detection and control [3], [4], [5], [6], [7], [8]. Evidence suggests that patients diagnosed with the disease exhibit different clinical behaviour according to the various pathological and biological characteristics of the tumour; thus, recommending different therapeutic strategies.

Earlier analytic studies on gene expressions revealed that the response of the mammary carcinoma cell to treatment is determined by intrinsic molecular characteristics that could be probed. The pioneer molecular portrait presented by Sorlie et al., classified breast cancer into five intrinsic subtypes with distinct clinical outcomes, i.e., luminal $A$, luminal B, HER2 over-expression, basal and normal-like tumours [9], [10]. Later on, immunohistochemical (IHC) assays categorised breast cancer into three major adopted phenotypes; the Luminal, HER2 enriched and Triple Negative (TN).

TN breast cancer is considered a heterogeneous group that comprises the basal subtypes which are reported to be more frequent among younger age patients and exhibit more aggressive nature with limited therapeutic options and high risk of recurrence [11], [12], [13]. On the other 
hand, the luminal-like tumours, that express hormone receptor, are the most common subtypes that carry a good prognosis. They usually respond well to hormonal treatment but poorly to conventional chemotherapy. While Luminal A could be adequately controlled with endocrine treatment, luminal B (triple positive TP) phenotypes often tend to be more proliferative, yielding relatively higher grade and recurrent tumours; thus, recommending combined chemotherapy and hormonal treatment [10], [14].

Whereas few previous studies registered the various breast cancer IHC subtypes among Iraqi patients [5], [6], [15], [16], [17], [18], reported data on their different behaviours and outcomes to remain scanty.

This study aims at providing further information on the clinical and pathological presentations of TN Iraqi breast cancer patients as compared to the other variants focusing on the triple positive (TP) and HER2 enriched phenotypes.

\section{Material and Methods}

The present study comprised 486 Iraqi female patients with a histopathologically confirmed diagnosis of mammary carcinoma registered between 2015 and 2017 at the Oncology Teaching Hospital and the National Cancer Research Center, Baghdad, Iraq. The studied clinical and pathological parameters were obtained from the case sheet records and pathology reports of the corresponding patients and included the age at diagnosis, tumour type, grade and size, lymph node status and the stage of the disease at presentation. Written consents were obtained from all the patients enrolled in the present work to use the relevant recorded information and approval of the study design was given by the Ethical Committee of the National Cancer Research Center of Baghdad University following the ethical standards laid down by the Declaration of Helsinki.

The reported data were reassessed to document the requested variables. Pathologically, breast cancers were typed according to the WHO classification [19] and graded following the modified Nottingham Bloom-Richardson categorisation [20]. The UICC TNM System was adopted to classify the clinical stage of the disease at presentation [21]. Evaluation of the Estrogen receptor (ER), Progesterone receptor (PR) and HER2 contents of the primary tumours was performed through IHC staining of the formalin-fixed paraffin-embedded tissue blocks using Dako kits (Denmark) including the specific monoclonal antibodies [14], [15].

The major registered receptor-defined subtypes were: - Luminal A (ER/PR positive/HER2 negative); - Luminal B/Triple Positive (ER/PR
positive/HER2 positive); - HER2 Enriched (ER/PR negative/HER2 positive); and - Triple Negative (ER/PR negative/HER2 negative).

Other recorded subtypes included: - ER (positive)/PR (negative)/HER2 (positive); - ER (negative)/PR (positive)/HER2 (positive); - ER (positive)/PR (negative)/HER2 (negative); and - ER (negative)/PR (positive)/HER2 (negative).

Accordingly, patients were classified into five groups: TN (Group I); TP (Group II); Luminal A (Group III); HER2 enriched (Group IV); and all other subtypes (Group V).

Statistical correlation to compare the demonstrated clinical and pathological features of the different breast cancer subtypes was carried out using SPSS version 16.0 statistical program. Categorical data were presented by frequencies and percentages. Chi-square test was used to assess the association between the different variables. $P$ values, less or equivalent to 0.05 , were considered significant.

\section{Results}

IHC examination of the diagnosed breast cancer tissue specimens belonging to 486 patients revealed that the total rates of ER, PR and HER2 positive tumour contents were equivalent to $68.5 \%$, $66.2 \%$ and $29.6 \%$ respectively. The major registered subtype was the Luminal $A(E+/ P+/ H-)$ which was encountered in 230 patients $(47.3 \%)$, followed by Triple Negative (E-/P-/H-) in 71 patients $(14.6 \%)$, Luminal $\mathrm{B} /$ Triple Positive $(\mathrm{E}+/ \mathrm{P}+/ \mathrm{H}+)$ in 66 patients $(13.6 \%)$ and HER2 Enriched $(\mathrm{E}-\mathrm{P}-\mathrm{H}+\mathrm{H})$ in 56 patients $(11.5 \%)$. Other encountered phenotypes were rare and included in order of frequency: $(\mathrm{E}+/ \mathrm{P}-/ \mathrm{H}-)$ in 22 cases $(4.5 \%) ;(\mathrm{E}-/ \mathrm{P}+/ \mathrm{H}-)$ in 19 cases $(3.9 \%) ;(\mathrm{E}+/ \mathrm{P}$ $/ \mathrm{H}+)$ in 15 cases $(3.1 \%)$ and $(E-/ P+/ H+)$ in seven cases (1.4\%) (Figure 1, Table 1).

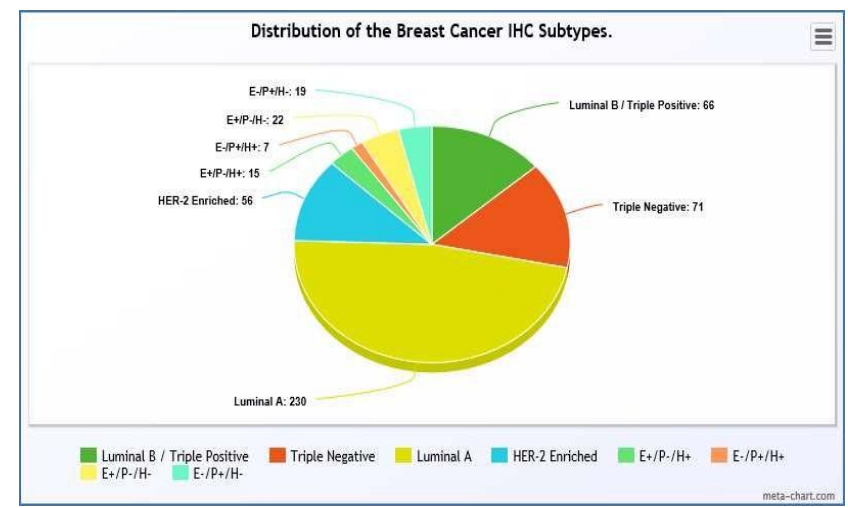

Figure 1: Frequency distribution of Iraqi breast cancer IHC subtypes

Table 2 illustrates the clinical and pathological presentations of the TN breast cancer subtype compared to the TP/Luminal B, HER2 enriched and 
Luminal A phenotypes. Significant differences were noted among the different studied groups concerning the age of the patients at presentation $(p<0.05)$. Patients exhibiting the TN subtype were significantly younger than the rest of the groups $(69 \%$ under the age of 50 years versus $52 \%$ overall).

Table 1: Overall rates of the reported breast cancer subtypes among Iraqi patients

\begin{tabular}{|c|c|c|c|c|c|c|c|}
\hline & IHC Subtype & $\begin{array}{c}\mathrm{ER}^{*} \\
\text { Status }\end{array}$ & $\begin{array}{l}\mathrm{PR}^{* *} \\
\text { Status }\end{array}$ & $\begin{array}{l}\text { HER2 }{ }^{* * *} \\
\text { Status }\end{array}$ & $\begin{array}{l}\text { IHC } \\
\text { Phenotypes }\end{array}$ & $\begin{array}{l}\text { Total } \\
\text { No. }\end{array}$ & $\begin{array}{c}\text { Total } \\
\%\end{array}$ \\
\hline 1 & $\begin{array}{l}\text { Luminal } \\
\text { B/Triple } \\
\text { Positive }\end{array}$ & $\mathrm{E}+$ & $\mathrm{P}+$ & $\mathrm{H}+$ & $\mathrm{E}+/ \mathrm{P}+/ \mathrm{H}_{+}$ & 66 & 13.6 \\
\hline 2 & Triple Negative & $E-$ & P. & $\mathrm{H}-$ & E-/P-/H- & 71 & 14.6 \\
\hline 3 & Luminal A & $E_{+}$ & $\mathrm{P}_{+}$ & $\mathrm{H}-$ & $\mathrm{E}+/ \mathrm{P}+/ \mathrm{H}-$ & 230 & 47.3 \\
\hline 4 & $\begin{array}{l}\text { HER-2 } \\
\text { Enriched }\end{array}$ & $\mathrm{E}-$ & P- & $\mathrm{H}_{+}$ & $\mathrm{E}-/ \mathrm{P}-/ \mathrm{H}_{+}$ & 56 & 11.5 \\
\hline 5 & $\mathrm{E}+/ \mathrm{P}-/ \mathrm{H}_{+}$ & $E_{+}$ & P- & $\mathrm{H}_{+}$ & $\mathrm{E}+/ \mathrm{P}-/ \mathrm{H}_{+}$ & 15 & 3.1 \\
\hline 6 & $\mathrm{E}-/ \mathrm{P}+/ \mathrm{H}_{+}$ & $\mathrm{E}-$ & $\mathrm{P}+$ & $\mathrm{H}_{+}$ & $\mathrm{E}-/ \mathrm{P}+/ \mathrm{H}_{+}$ & 7 & 1.4 \\
\hline 7 & $\mathrm{E}+/ \mathrm{P}-/ \mathrm{H}-$ & $E_{+}$ & P- & $\mathrm{H}-$ & $\mathrm{E}+/ \mathrm{P}-/ \mathrm{H}-$ & 22 & 4.5 \\
\hline & $\mathrm{E}-/ \mathrm{P}+/ \mathrm{H}-$ & $\mathrm{E}-$ & $\mathrm{P}_{+}$ & $\mathrm{H}-$ & $\mathrm{E}-/ \mathrm{P}+/ \mathrm{H}-$ & 19 & 3.9 \\
\hline Total & & & & & & 486 & 100 \\
\hline
\end{tabular}

Although the rate of Lobular carcinoma was higher among group III (Luminal A), yet the differences in frequencies of the various histologic types of breast cancer were not statistically significant.

Table 2: Clinical and tumour characteristics categorized according to the examined breast cancer subtypes

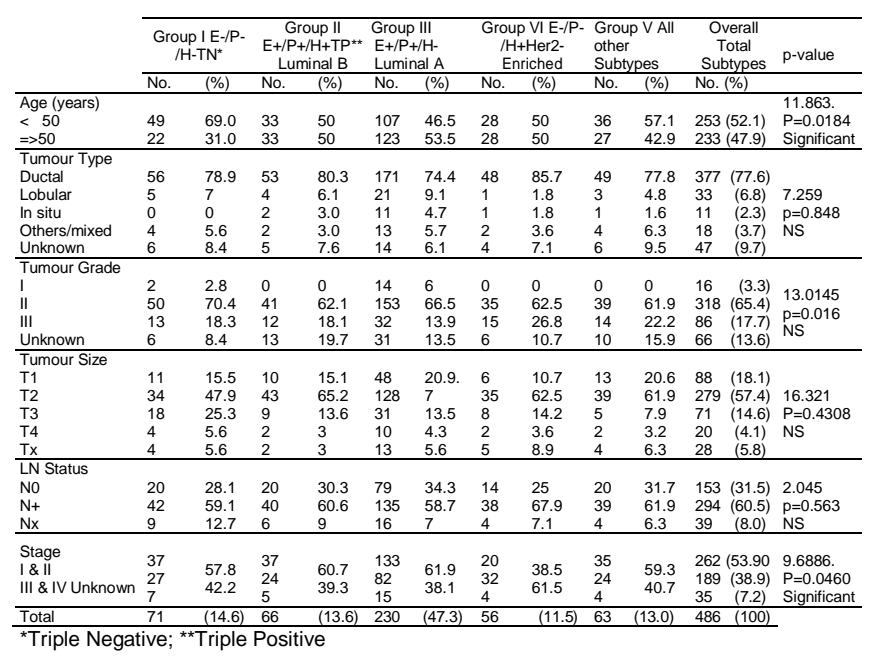

Likewise, whereas the highest frequency of poorly differentiated mammary carcinomas was observed among group IV (HER2) subtype (26.8\% versus $17.7 \%$ overall), such difference was not significant. Larger size tumours (T3 and T4) were more common in patients with the group I (TN) phenotype (30.9\% versus $16.6 \%, 17.8 \%, 17.8 \%$ and $11.1 \%$ in groups II, III, and IV and V respectively). More than two-thirds of patients in group IV (HER2) presented with metastatic lymph node involvement $(67.9 \%)$; that rate was higher than the other subtypes. Nevertheless, Chi-square statistics failed to reveal any significant variations between the studied groups regarding tumour size or nodal status. On the other hand, a statistical difference in the distribution of breast cancer stages was displayed $(p<0.05)$; with significantly more advanced stages (III and IV) noted in patients with HER2 enriched subtypes (61.5\%) compared to $42.2 \%, 39.3 \%$ and $38.1 \%$ in groups I, II and III respectively.

\section{Discussion}

Cancer is currently forming a major public health concern in Iraq; being responsible for the second cause of death among the general population [2], [22], [23]. Iraqi studies, in particular, have displayed the emerging dilemma of controlling breast cancer, the most common registered malignancy, which is increasingly diagnosed alarmingly among middle-aged females at quite advanced stages [4], [5], [6], [7], [8], [23]. It has been well established that racial disparities contribute to the various morphologies and presentations of breast cancer among patients in different ethnic groups reflecting the reported discrepancy in incidence, prognosis and survival from the disease [24], [25], [26], [27]. The molecular diversity of breast cancer illustrated in genomic analytic studies promoted the development of targeted therapies to the genetic alterations that drive certain identified cancer subtypes. The registered frequencies of ER+, PR+ and HER2+ breast cancers in the present work were $68.5 \%, 66.2 \%$ and $29.6 \%$ respectively. Whereas the corresponding figures from western studies are significantly higher for $\mathrm{ER}+$ and $\mathrm{PR}+$ breast cancers, they are statistically lower for HER2 + tumours contributing to better outcomes of the disease in well-developed regions of the world [5], [24], [25], [26], [27], [28], [29].

As observed in earlier studies from Iraq [5], [15], [16], [17], [18] and the literature [9], [10], [11], [12], [13], [14], [24], [25], [26], [27], [28], [29], [30], [31], [32], [33] the major registered breast cancer subtype was Luminal A $(47.3 \%)$ that comprises positive hormone receptors in the absence of HER2 overexpression; stimulating the favorable biological behavior of the disease in the affected patients. While the displayed rate is close [29] and almost higher than those documented in surveys from Arab countries [30], [31], yet it is significantly lower than those reported in Western studies [5], [24], [25], [26], [27], [28]. Focusing on molecular characteristics and management implications of breast cancer in Arab populations, it was noted that disparities in these regions were not only confined to the clinicopathological features but existed as well at the molecular levels as reflected in the relevant genomic expression profiles [5], [27], [29], [30], [31]. A recent study on the comparative behaviour of breast cancer among Iraqi and British patients pointed out to heterogeneity of the underlying tumour biology that reflected genetic susceptibility. The authors concluded 
that the significantly younger ages and advanced stages at the presentation of breast cancer among Iraqi patients, associated with the higher rates of TN and HER2 enriched phenotypes, recommended comprehensive assessment of the surrogate subtypes to ensure effective approaches in the management of the disease in Iraq [5]. Such higher rates of aggressive breast cancer subtypes among patients from low-middle income countries compared to those living in high-income societies were illustrated in earlier surveys [27], [29], [30], [31], [32], [33]. The second prevalent breast cancer subtype observed in the present work (14.6\%) was the TN which is characterised by the negative expressions of ER, PR and HER2.

Interestingly that frequency was close to the rate recorded in the Annual Report to the Nations on the incidence of breast cancer subtypes in the US [28]; highlighting the significantly low prevalence of hormone receptor-negative tumours among the American patients. Consistent with the findings displayed earlier by other investigators, patients bearing this subtype in our study were significantly younger than those exhibiting the other phenotypes and presented with larger size tumours at the time of diagnosis [11], [12], [13]. However, they were less likely to have poorly differentiated tumours and positive lymph node involvement than group IV; the HER2-enriched tumour counterparts. Whereas previous reports showed that TN breast cancer tumours with more positive axillary lymph node, higher clinical stages and histological grades leading to aggressive clinical behaviour [34], [35], others demonstrated that TN encompasses a wide spectrum of entities possessing different biological and clinical attitudes including low-grade disease with indolent behaviour and favourable outcome [36], [37].

In general, patients exhibiting the HER2 enriched variant, which constituted $11.5 \%$ of total subtypes in the present work, displayed the highest frequency of poorly differentiated cancers and metastatic lymph nodes. It has been recorded in the literature that between $15-25 \%$ of breast cancers possess overexpression of HER2 and yield unfavourable clinical outcome [28], [38], [39]. The registered rates of HER2 + subtypes in the Arab series are quite higher [29], [40]; pointing out to the elevated prevalence of less differentiated tumours in the region [29], [30], [31], [40], [41]. Such regional and ethnic differences in the grades of the tumour are most probably related to genetic, biological and environmental factors. TP Luminal B subtype formed about $13.6 \%$ in the present study; close to the findings reported in previous studies from Iraq [5], [6], [15], [16], [18], and the neighboring countries [41], [42]. In a recent survey performed on a cohort of Iraqi patients presenting with breast cancer, no significant differences were noted in the clinicopathological presentations of patients with this phenotype compared to the others apart from the variation in the distribution of tumour types; where infiltrative ductal carcinomas were more common [16]. That was in contrast to the findings observed in another study which showed that invasive ductal carcinomas were preponderant among the TN subtypes [36]. Similar to other studies [43], the data of this work did not reveal any statistical differences in the distribution of the histological types among the examined groups, though the rate of lobular carcinoma was more common among patients with Luminal A.

Concerning the breast cancer stage at presentation, our results revealed a significant difference in the distribution among the various groups $(p<0.05)$; with the highest frequency of advanced stages (III and IV) being observed among those harbouring the HER2 enriched subtypes. It has been displayed in the literature that hormone-receptorpositive breast cancer expressions are often associated with earlier stages at presentation and that HER2+ impact is reflected by poorly differentiated tumours and advanced stages [39].

A recently published Iraqi study correlating the stage of breast cancer at the time of diagnosis with the clinicopathological characteristics of the affected patients demonstrated that $64.4 \%$ and $67.2 \%$ exhibiting Luminal A and Luminal B subtypes respectively were diagnosed at Stages I and II whereas $68 \%$ and $62 \%$ of those harbouring the TN and HER2+ respectively presented at advanced stages (III and IV) [6]. Comparative retrospective evaluation of the clinical features and survival outcomes of 1134 invasive breast cancer subtypes showed that the overall five-year survival was almost similar in TN and HER2 subtypes, nevertheless, subjects with HER2 presented at later stages with more frequent local recurrences [44].

In conclusion, patients within the TN group were statistically younger and exhibited larger tumour sizes than others. On the other hand, poorly differentiated tumours and metastatic lymph node involvement were more commonly encountered among patients with HER2 subtype who presented with significantly more advanced stages at the time of diagnosis. Adopting molecular subtype classification of breast cancer, as a cost-effective, reliable clinical investigation in countries with limited resources, is recommended to provide a feasible tool for assessing the response to therapy and to serve as a valuable prognostic marker in the management of aggressive forms of the disease among younger patients.

\section{Author Contribution}

Prof. Dr Nada Alwan, designed the study, analysed the results, wrote the manuscript and presented the final version. Mr Furat Nidhal supported 
in providing relevant information, data entry and data analysis.

\section{Acknowledgement}

We thank gratefully the working staff at the Main Training Center for Early Detection of Breast Cancer, Medical City Teaching Hospital and the Cancer Registry Section of the National Cancer Research Center, Baghdad University.

\section{References}

1. Globocan 2018. World Health Organization. International Agency for Research on Cancer (IARC) Press. Geneva, Switzerland, 2018.

2. Iraqi Cancer Board (2016). Results of the Iraqi Cancer Registry 2015. Baghdad, Iraqi Cancer Registry Center, Ministry of Health, 2018.

3. Von Karsa L, Qiao Y, Ramadas K, Keita N, Arrossi S, Boyle P, Alwan N, Sankararanarayanan R. Prevention/Screening Implementation, in Stewart BW and Wild CP (eds): World Cancer Report 2014. Lyon, France, World Health Organization International Agency for Research on Cancer, 2014

4. Alwan N. Breast Cancer among Iraqi Women: Preliminary Findings from a Regional Comparative Breast Cancer Research Project. J Glob Oncol. 2016; 2(5):255-258.

https://doi.org/10.1200/JGO.2015.003087 PMid:28717711 PMCid:PMC5493264

5. Alwan, N, Kerr D, Al-Okati D, et al. Comparative study on the clinic-pathological profiles of breast cancer among Iraqi and British patients. The Open Public Health Journal. 2018; 11(1):177-191. https://doi.org/10.2174/1874944501811010177

6. Alwan NA, Tawfeeq FN, Maallah MH, et al. The Stage of Breast Cancer at the Time of Diagnosis: Correlation with the Clinicopathological Findings among Iraqi Patients. J Neoplasm. 2017; 2(3):22. https://doi.org/10.21767/2576-3903.100020

7. Alwan N. Breast Cancer: Demographic Characteristics and Clinico-pathological Presentation of Patients in Iraq. Eastern Mediterranean Health Journal. 2010; 16:1073-1078. https://doi.org/10.26719/2010.16.11.1159

8. Alwan N. Establishing Guidelines for Early Detection of Breast Cancer in Iraq. Int J of Advanced Research. 2015; 3(12):539-555.

9. Sørlie T, Perou CM, Tibshirani R, et al. Gene expression patterns of breast carcinomas distinguishes tumor subclasses with clinical implications. Proc Natl Acad Sci USA. 2001; 98 (19):1086974. https://doi.org/10.1073/pnas.191367098 PMid:11553815 PMCid:PMC58566

10. Weigelt B, Baehner FL, Reis-Filho JS. The contribution of gene expression profiling to breast cancer classification, prognostication and prediction: a retrospective of the last decade. J Pathol. 2010; 220:263-280. https://doi.org/10.1002/path.2648 PMid:19927298

11. Boyle P. Triple-negative breast cancer: epidemiological considerations and recommendations. Ann Oncol. 2012; 23(6):712. https://doi.org/10.1093/annonc/mds187 PMid:23012306

12. Lin NU, Vanderplas A, Hughes ME, et al. Clinicopathologic features, patterns of recurrence, and survival among women with triple-negative breast cancer in the national comprehensive cancer network. Cancer. 2012; 118:5463-72. https://doi.org/10.1002/cncr.27581 PMid:22544643 PMCid:PMC3611659

13. Urru SA, Gallus S, Bosetti C, et al. Clinical and pathological factors influencing survival in a large cohort of triple-negative breast cancer patients. BMC Cancer. 2018; 18(56):1-12. https://doi.org/10.1186/s12885-017-3969-y PMid:29310602 PMCid:PMC5759886

14. Abubakar M, Guo C, Koka J, Sung H, et al. Clinicopathological and epidemiological significance of breast cancer subtype reclassification based on p53 immunohistochemical expression. npj Breast Cancer. 2019; 5(20):1-9. https://doi.org/10.1038/s41523019-0117-7 PMid:31372496 PMCid:PMC6658470

15. Muallah FH, Tawfeeq FN, Alwan NA. Breast Cancer Subtypes among Iraqi Patients: Identified by Their ER PR and HER2 Status. Journal of the Faculty of Medicine. 2017; 59(4):303-7. https://doi.org/10.32007/med.1936/ifacmedbagdad.v59i4.6

16. Alwan NAS, Mualla F, Naqash M, et al. Clinical and Pathological Characteristics of Triple Positive Breast Cancer among Iraqi Patients. Gulf Journal of Oncology. 2017; 25:6-15.

17. Majid R, Hassan HA, Muhealdeen DN, et al. Breast cancer in Iraq is associated with a unimodally distributed predominance of luminal type $B$ over luminal type $A$ surrogates from young to old age. BMC Women's Health. 2017; 17(27):1-8. https://doi.org/10.1186/s12905-017-0376-0 PMid:28388952 PMCid:PMC5383947

18. Alwan NA. Tumor Characteristics of Female Breast Cancer: Pathological Review of Mastectomy Specimens Belonging to Iraqi Patients. World Journal of Breast Cancer Research. 2018; 1(1):1-3.

19. Lakhani SR, Ellis IO, Schnitt SJ, et al. WHO Classification of Tumours of the Breast. Fourth Edition, WHO Classification of Tumours, Volume 4, IARC, 2012.

20. Elston CW, Ellis IO. Pathological prognostic factors in breast cancer. I. The value of histological grade in breast cancer: Experience from a large study with long-term follow-up. Histopathology. 2002; 41:154-161.

21. Sobin LH, Gospodarowicz MK, Wittekind C, editors. TNM classification of malignant tumours. John Wiley \& Sons; 2011. https://doi.org/10.1002/9780471420194.tnmc29

22. Alwan NAS, Kerr D. Cancer Control in War-Torn Iraq, The Lancet Oncology, 2018; 19(3):291-2. https://doi.org/10.1016/S1470-2045(18)30135-9

23. Warner ET, Tamimi RM, Hughes ME, Ottesen RA, Wong YN, Edge SB, Theriault RL, Blayney DW, Niland JC, Winer EP, Weeks JC. Racial and ethnic differences in breast cancer survival: mediating effect of tumor characteristics and sociodemographic and treatment factors. Journal of clinical oncology. 2015; 33(20):2254-2261. https://doi.org/10.1200/JCO.2014.57.1349 PMid:25964252 PMCid:PMC4486344

24. Brennan M. Breast cancer in ethnic minority groups in developed nations: case studies of the United Kingdom and Australia. Maturitas. 2017; 99:16-19. https://doi.org/10.1016/i.maturitas.2017.01.015 PMid:28364863

25. Chen DA, Song CG, Ouyang QW, et al. Differences in breast cancer characteristics and outcomes between Caucasian and Chinese women in the US. Oncotarget. 2015; 6(14):12774-12782. https://doi.org/10.18632/oncotarget.3666 PMid:25904050 PMCid:PMC4494973

26. Sengal AT, Mukhtar NS, Vetter M, et al. Comparison of Receptor- Defined Breast Cancer Subtypes between German and Sudanese Women: A Facility-Based Cohort Study. Journal of Global Oncology. 2017:1-12.

https://doi.org/10.1200/JGO.2017.010082 PMid:30241184 PMCid:PMC6180747

27. Kohler BA, et al. Annual Report to the Nation on the Status of Cancer, 1975 -2011, Featuring Incidence of Breast Cancer

Subtypes by Race/Ethnicity, Poverty, and State. JNCl. 2015;

107(6):djv048. https://doi.org/10.1093/inci/div048 PMid:25825511 PMCid:PMC4603551

28. Khabaz MN. Immunohistochemistry Subtypes (ER/PR/HER) of 
Breast Cancer: Where Do We Stand in the West of Saudi Arabia? Asian Pac J Cancer Prev. 2014; 15(19):8395-8400. https://doi.org/10.7314/APJCP.2014.15.19.8395 PMid:25339035

29. Sengal AT, Haj-Mukhtar NS, Elhai AM, et al.

Immunohistochemistry defined subtypes of breast cancer in 678

Sudanese and Eritrean women; hospitals based case series. BMC Cancer. 2017; 804:1-9. https://doi.org/10.1186/s12885-017-3805-4 PMid:29191181 PMCid:PMC5710067

30. Chouchane L, Boussen H, Sastry KSR. Breast cancer in Arab populations: molecular characteristics and disease management implications. The Lancet Oncology. 2013; 14(10):417-424. https://doi.org/10.1016/S1470-2045(13)70165-7

31. Amadori D, Serra $P$, Bravaccini $S$, et al. Differences in biological features of breast cancer between Caucasian (Italian) and African (Tanzanian) populations. Breast Cancer Res Treat. 2014; 145:177-183. https://doi.org/10.1007/s10549-014-2903-0 PMid:24658893

32. Adjei EK, Owusu-Afriyie O, Awuah B, et al. Hormone receptors and Her2 expression in breast cancer in sub-Saharan Africa. A comparative study of biopsies from Ghana and Norway. Breast $\mathrm{J}$. 2014; 20:308-311. https://doi.org/10.1111/tbj.12261 PMid:24708149

33. Aksoy S, Dizdar O, Harputluoglu H, Altundag K. Demographic, clinical, and pathological characteristics of Turkish triple-negative breast cancer patients: single center experience Annals of Oncology, 2007; 18(11):1904-1906. https://doi.org/10.1093/annonc/mdm487 PMid:17993632

34. Yang DH, Liu H, Zhao J. Clinicopathologic Features and Prognosis of Triple Negative Breast Cancer. Chinese Clinical Oncology. 2008; 35:501-504.

35. Fusco N, Geyer FC, De Filippo MR, et al. Genetic events in the progression of adenoid cystic carcinoma of the breast to highgrade triple-negative breast cancer. Modern Pathology. 2016; 29:1292-1305. https://doi.org/10.1038/modpathol.2016.134 PMid:27491809 PMCid:PMC5083185

36. Pareja F, Geyer FC, Marchiò C, et al. Triple-negative breast cancer: the importance of molecular and histologic subtyping, and recognition of low-grade variants. npj Breast Cancer. 2016; 2:1-11. https://doi.org/10.1038/npjbcancer.2016.36 PMid:28721389

PMCid:PMC5515338
37. Howlader N, Altekruse SF, Li Cl, et al. US incidence of breast cancer subtypes defined by joint hormone receptor and HER2 status. J Natl Cancer Inst. 2014; 106(5).

https://doi.org/10.1093/jnci/dju055 PMid:24777111 PMCid:PMC4580552

38. Alqaisi A, Chen L, Romond E, Chambers M, Stevens M, Pasley $\mathrm{G}$, Awasthi M, Massarweh S. Impact of estrogen receptor (ER) and human epidermal growth factor receptor-2 (HER2) co- expression on breast cancer disease characteristics: implications for tumor biology and research. Breast Cancer Res Treat. 2014; 148:437444. https://doi.org/10.1007/s10549-014-3145-x PMid:25257728

39. Errahhali ME, Errahhali ME, Ouarzane M, El Harroudi T, Afqir $\mathrm{S}$, Bellaoui M. First report on molecular breast cancer subtypes and their clinico-pathological characteristics in Eastern Morocco: series of 2260 cases. BMC women's health. 2017; 17(1):3. https://doi.org/10.1186/s12905-016-0361-z PMid:28068979 PMCid:PMC5223366

40. Dawood S, Hu R, Homes MD, Collins LC, Schnitt SJ, Connolly $J$, Colditz GA, Tamimi RM. Defining breast cancer prognosis based on molecular phenotypes: results from a large cohort study. Breast Cancer Res Treat. 2011; 126(1):185-92.

https://doi.org/10.1007/s10549-010-1113-7 PMid:20711652 PMCid:PMC3026074

41. Shomaf M, Masad J, Najjar S, Faydi D. Distribution of breast cancer subtypes among Jordanian women and correlation with histopathological grade: molecular sub-classification study. J R Soc Med Sh Rep. 2013; 4(10):1-6.

https://doi.org/10.1177/2042533313490516 PMid:24319578 PMCid:PMC3831862

42. Quu J, Xue X, Hu C, et al. Comparison of Clinicopathological Features and Prognosis in Triple- Negative and Non-Triple Negative Breast Cancer. Journal of cancer. 2016; 7(2):167-173. https://doi.org/10.7150/ica.10944 PMid:26819640 PMCid:PMC4716849

43. Onitilo AA, Engel JM, Greenlee RT, Mukesh BN. Breast cancer subtypes based on ER/PR and Her2 expression: comparison of clinicopathologic features and survival. Clinical medicine \& research. 2009; 7(1-2):4-13. https://doi.org/10.3121/cmr.2008.825 